\title{
ANALISIS CETAKAN INJEKSI PLASTIK IMPELLER POMPA AIR PADA KAPAL NELAYAN APLIKASI CAD/CAE/CAM
}

\author{
Nur Indah dan Ibnu Arrifin \\ Universitas Mercu Buana Jakarta \\ e-mail: nur.indah@mercubuana.ac.id, arrifine619@gmail.com
}

\begin{abstract}
Most of the fishermen in Indonesia, using pumps to drain water in the ship. The use of pumps in sea water often lead to rapid corrosion, especially on the impeller. Impeller manufacture of plastic materials is an alternative to solve this problem. Stages in the designing mould of plastic impeller is with $3 D$ and $2 D$ drawing, choose a suitable polymer material, making mold of product, selecting components of mold and simulating the result. In designing mould of plastic impeller used software to simulate the plastic mould with mould parameters plastic inserts to get the best results before the completion of production. As for plastic injection machine that is used to clamp force 1000 ton capacity with 8 pieces in each injection products and using nylon material, 281, $1^{\circ} \mathrm{C}$ temperature parameters, 62 sec of cycle time and 80,552 MPa pressure.
\end{abstract}

Keywords: Plastic Molding, Injection Process, Plastic Impeller, CAD/CAE/CAM Software.

\section{PENDAHULUAN}

Pompa adalah alat untuk memindahkan fluida cair yang sering digunakan nelayan untuk menguras air yang masuk kedalam kapal. Sebagian besar nelayan menggunakan pompa sentrifugal tipe CP100 karena kebutuhan kapasitas yang tidak terlalu besar. Korosi adalah masalah utama yang sering terjadi karena penggunaan pompa pada air laut. Pompa yang rusak hanya mengalami kerusakan pada bagian impeller dan cukup menggantikannya dengan impeller yang baru untuk memperbaikinya. Namun, spare part untuk menggantikannya sangat sulit ditemukan di pasaran dan akhirnya mereka harus membeli satu set atau membeli pompa yang baru [1].

Pompa air yang digunakan saat ini, banyak menggunakan impeller dengan bahan kuningan atau stainless karena lebih tahan korosi dan tahan aus tetapi harga dari bahan kuningan umumnya cukup mahal. Alternatif lain, digunakan impeller dari bahan polimer yang tidak korosif dan tahan aus namun belum ada perusahaan lokal yang memproduksinya dan harus import dengan harga masih relatif mahal.

Seiring perkembangan teknologi, program-program desain sudah banyak digunakan engineer dalam membuat suatu rancangan untuk memenuhi kebutuhan dan menganalisis masalah yang terjadi di lapangan. Teknologi desain dengan basis CAD (Computer Aided Design), CAE (Computer Aided Engineering) dan CAM (Computer Aided Manufacture) saat ini digunakan hampir di setiap industry [2]. Pemanfaatan teknologi ini untuk perancangan cetakan injeksi plastik dalam pembuatan impeller plastik sangat diperlukan untuk mendapatkan desain rancangan dan parameter pengerjaan yang optimal. Dalam hal ini, proses menentukan rancangan cetakan injeksi plastik dilakukan dengan simulasi flow injection pada software dengan berbagai faktor pertimbangan.

Harapan yang ingin dicapai dengan memanfaatkan teknologi ini yaitu meminimalkan kesalahan dalam proses produksi impeller dan sebagai alternatif untuk memudahkan dan mengurangi biaya pembelian impeller pompa plastik yang masih import dan dapat bersaing dengan produk sejenis yang dihasikan pihak lain.

\section{METODOLODI PENELITIAN}

Diagram alir pada penelitian ini ditunjukan pada Gambar 1.

\section{Pemilihan Bahan Polimer}

Pada penelitian ini, proses perancangan diawali dengan pemilihan bahan polimer dengan metode pengujian bahan plastik menurut standar ASTM (American Standard Testing Methode), yang mana prinsip dari pengujian ini adalah dengan memberikan beban gaya yang berlawanan arah 
pada kedua ujung specimen bahan material yang diuji, sehingga kekuatan dari bahan yang diuji dapat diketahui [3]. Setelah melihat hasil dari pengujian beberapa bahan polimer maka diambil satu bahan yang paling cocok sesuai kebutuhan yaitu bahan nilon PA66 dengan hasil pengujian seperti Tabel 1.

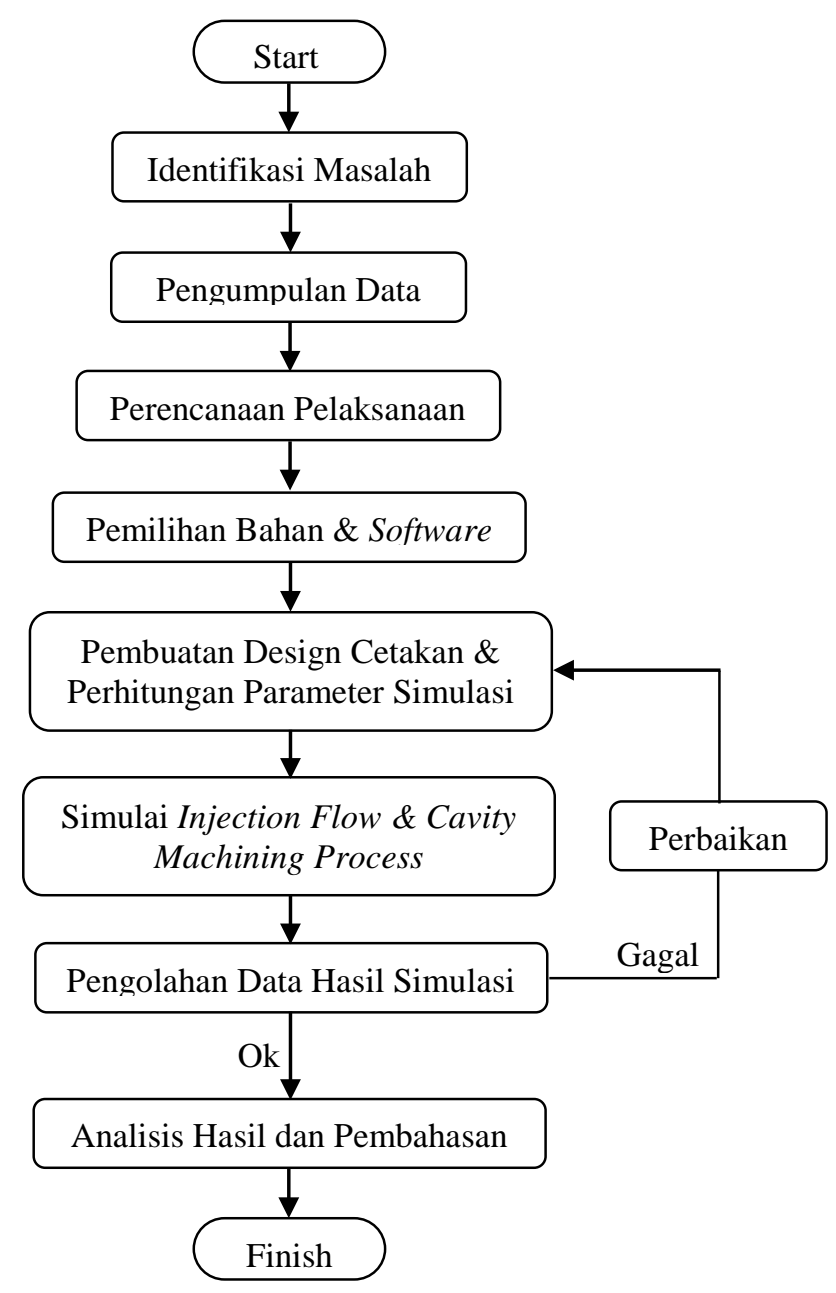

Gambar 1. Diagram alir penelitian

Tabel 1. Hasil pengujian nilon PA66

\begin{tabular}{cc}
\hline Metode & Hasil Uji \\
\hline Tensile Strength & $30-50 \mathrm{MPa}$ \\
Flexural Modulus & $897-4138 \mathrm{MPa}$ \\
Izod Impact Strength & $105-640 \mathrm{~J} / \mathrm{m}$ \\
Hardenes & $75-120 \mathrm{R} \mathrm{Scale}$ \\
\hline
\end{tabular}

\section{Desain Produk}

Pada dasarnya, pembuatan desain produk impeller mengacu pada produk yang sudah ada hanya saja digambar ulang dengan dimensi dan visual yang sama dengan menggunakan software AutoCAD.

\section{Perhitungan Volume dan Massa Siklus}

Perancangan ini digunakan proses part fill analysis pada Autodesk Inventor didapatkan hasil volume produk $\left(\mathrm{V}_{\mathrm{p}}\right)$ adalah $12877,7 \mathrm{~mm}^{3}$. Autodesk Inventor merupakan sebuah program dengan kemampuan pemodelan 3D solid untuk proses pembuatan objek prototipe 3D secara visual, 
simulasi, dan drafting beserta dokumentasi data-datanya, Dalam penelitian ini akan merumuskan metode dan prosedur pembuatan gambar 3D dengan menggunakan Autodesk Inventor dan menganalisis hasil produk dari model konstruksi 3D yang telah dibuat [4] yaitu:

Jumlah cavity: 8 pc

Massa jenis Nylon (PA66): 1150,9 gr $/ \mathrm{mm}^{3}$

Volume total sekali injeksi

$$
\begin{aligned}
\mathrm{V}_{\text {total }} & =\mathrm{V}_{\text {prod }}+\mathrm{V}_{\text {sprue }}+\mathrm{V}_{\text {runner }}+\mathrm{V}_{\text {gate }} \\
\mathrm{V}_{\text {tot }} & =103021,6+13417,9+10039,16+196=126674,7 \mathrm{~mm}^{3} \\
& =126,674 \mathrm{~cm}^{3}
\end{aligned}
$$

Massa total produk sekali injeksi,

$$
\begin{aligned}
\mathrm{m} & =\mathrm{V}_{\text {tot }} \mathrm{x} \rho(\text { PA66) } \\
& =126,674 \times 1,1509 \\
& =145,8 \text { gram }=0,146 \mathrm{~kg}
\end{aligned}
$$

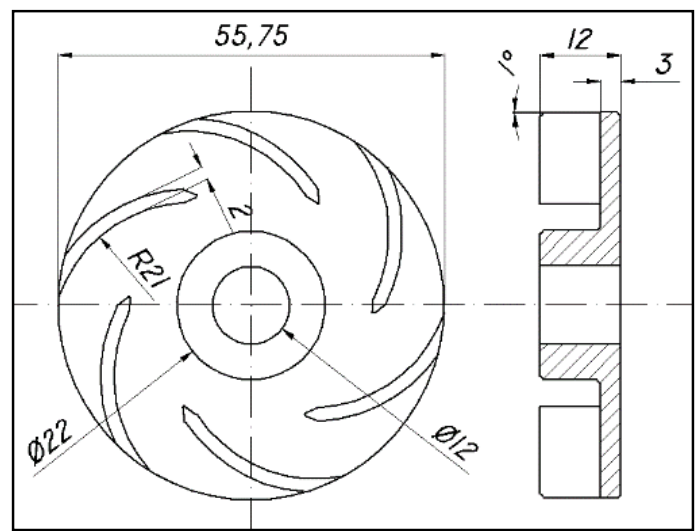

Gambar 2. Dimensi produk

\section{Perhitungan Gaya Klem Mesin}

Pada sebuah mesin yang sudah ada pencekaman material masih menggunakan klem dan mur baut yang menimbulkan kerusakan permukaan material, selain itu pembuatan lubang baut tidak efisien dan posisi klem dapat menimbulkan tabrakan dengan pisau potong [5], maka dengan itu perlu untuk melakukan perhitungan gaya klem dari sebuah mesin. Material yang digunakan untuk pembuatan core cavity adalah material baja $\mathrm{H}-13$ dengan tegangan yang diijinkan 5 ton/in ${ }^{2}=7,75$ $\mathrm{kg} / \mathrm{mm}^{2}$.

Gaya klem mesin [7] $=($ A Produk + A Runner $) \times \sigma$

Dengan:

$$
\begin{aligned}
& =(77.616,4+15,119) \times 7,75 \mathrm{~kg} / \mathrm{mm}^{2} \\
& =601.650 \mathrm{~kg}
\end{aligned}
$$

$$
\begin{aligned}
& A=\text { Luas Proyeksi }\left(\mathrm{mm}^{2}\right) \text { dan } \\
& \sigma=\text { Tegangan ijin }\left(\mathrm{kg} / \mathrm{mm}^{2}\right)
\end{aligned}
$$

Maka, mesin injeksi yang digunakan adalah tipe AD-1000 dengan gaya klem sebesar 1000 ton = $1.000 .000 \mathrm{~kg}$.

\section{Waktu Sekali Injeksi}

Unit untuk melakukan kontrol kerja dari Injection Molding, terdiri dari Motor untuk menggerakan screw, piston injeksi menggunakan Hydraulic system (sistem pompa) untuk mengalirkan fluida dan menginjeksi resin cair ke molding [6]. Waktu yang diperlukan untuk sekali 
siklus injeksi yaitu Injection High Time + Injection Hold Timer + Cooling Time + Machine Clamp Open and Close Time.

Dari hasil simulasi injeksi dan mesin injeksi yang digunakan, didapatkan hasil data sebagai berikut:

- Tipe mesin = AD-1000

- Diameter screw (d) $=105 \mathrm{~mm}$

- Ejection stroke $(\mathrm{E})=300 \mathrm{~mm}$

- Volume sekali injeksi $\left(\mathrm{V}_{\mathrm{p}}\right)=126674,7 \mathrm{~mm}^{3}$

- Aktual waktu injeksi (t) = 1,46 detik (mold fill analysis)

Maka debit cairan plastik ( $\tilde{v})$ yang masuk ke dalam cetakan adalah:

$\tilde{\mathrm{v}}=\frac{\mathrm{Vp}}{\mathrm{t}}$

$\tilde{\mathrm{v}}=\frac{126674,7}{1,46}=86.763,5 \mathrm{~mm}^{3} /$ detik

$\mathrm{A}_{\mathrm{scr}}=\frac{\pi}{4} \mathrm{x} \mathrm{d}^{2}$

$=\frac{\pi}{4} \times 105^{2}=8.659,01 \mathrm{~mm}^{2}$

$\tilde{\mathrm{v}}=\mathrm{q} \times \mathrm{A}_{\text {screw }}$

maka,

$$
\begin{aligned}
\mathrm{q} & =\frac{\tilde{\mathrm{v}}}{\mathrm{A}_{\mathrm{screw}}} \\
\mathrm{q} & =\frac{86763,5}{8659,01}=10,02 \mathrm{~mm} / \text { detik } \\
\mathrm{t}_{\mathrm{i}} & =\frac{\text { Ejection Stroke }(\mathrm{E})}{\mathrm{q}} \\
\mathrm{t}_{\mathrm{i}} & =\frac{300}{10,02}=29,94 \text { detik } \\
\text { mana, } & \\
\mathrm{q} & =\text { kecepatan screw (mm/detik) } \\
\mathrm{t}_{\mathrm{s}} & =\text { waktu injeksi (detik) }
\end{aligned}
$$

dimana,

Injection hold timer diperlukan agar gate seluruhnya membeku. Biasanya diambil 10 (detik) atau lebih. Machine clamp open and close time untuk jenis cetakan two plate adalah 5 detik. Hasil rekomendasi software, cooling time dengan bahan nilon cukup adalah 16,96 detik. Sehingga waktu 1 kali siklus yaitu:

$\mathrm{t}_{\text {siklus }}=29,94+10+5+16,96=61,9=62$ detik

\section{Desain Cetakan}

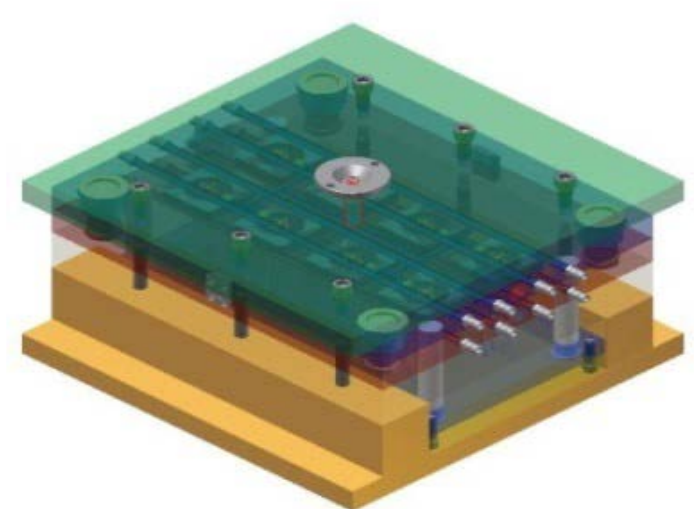

Gambar 3. Hasil desain cetakan 
Hasil dari desain cetakan menggunakan komponen-komponen standar moldbase yang tersedia pada software Autodesk Inventor dengan keterangan hasil sebagai berikut:

- Moldbase two plate standar HASCO K251

- 8 core \& 8 cavity

- Runner system H Balance

- 8 lubang pendingin langsung diameter $12 \mathrm{~mm}$

- 71 ejector pins (64 produk \& 7 runner system)

- Total dimensi 370 x 450 x 550 mm

\section{Perhitungan Proses Pemesinan}

Proses perhitungan waktu pemesinan untuk pembuatan core dan cavity digunakan software MasterCAM X5. Software ini mensimulasikan proses pemesinan dengan hasil berupa NC Code untuk input pada mesin CNC.

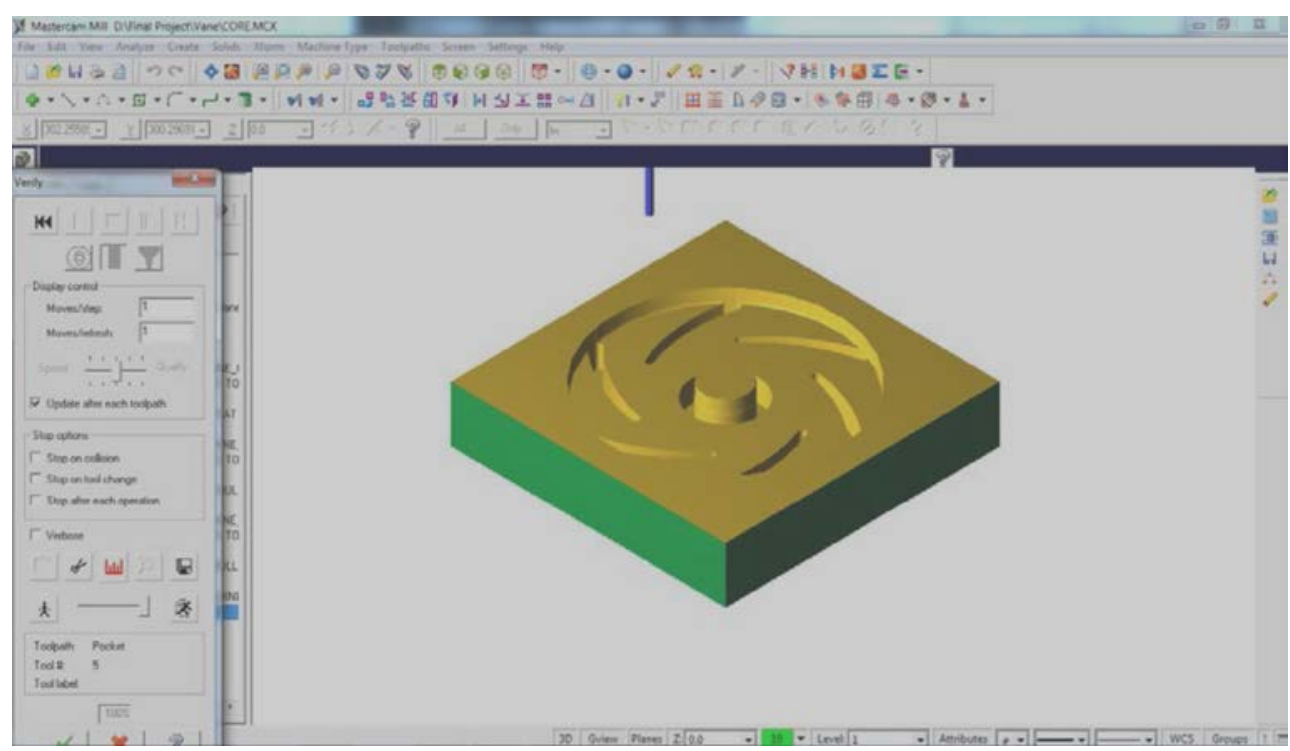

Gambar 4. Simulasi proses pengerjaan core cavity insert

Perhitungan proses pemesinan komponen lain meliputi proses milling, boring, grinding, finishing, assembling, dan quality.

Perhitungan waktu pemesinan core plate

Ukuran : $555 \times 455 \times 45 \mathrm{~mm}$

Bahan : S $50 \mathrm{C}$

a. Waktu pengerjaan milling

Kecepatan pemakanan (s) $=20 \mathrm{~mm} / \mathrm{menit}$

Tebal pemakanan benda $(\mathrm{t})=5 \mathrm{~mm}$

Tebal pemakanan (a) $=0,5 \mathrm{~mm}$

Jarak bebas cutter (la) $=10 \mathrm{~mm}$

$\mathrm{L}=l+\mathrm{d}+2 . l a$

$\mathrm{L}_{1}=2 .(550+25+2.10)=1190 \mathrm{~mm}$

$\mathrm{L}_{2}=2$. $(450+25+2.10)=990 \mathrm{~mm}$

Jumlah pemakanan (i) $=\frac{5}{0,5}=10$ kali $(2$ sisi $)$

Panjang langkah total

$$
\mathrm{L}=2180 \times 10=21800 \mathrm{~mm}
$$




$$
\begin{aligned}
& \operatorname{Tm}=\frac{L}{s} \\
& \operatorname{Tm}=\frac{21800}{20}=1090 \text { menit }
\end{aligned}
$$

b. Waktu pengerjaan boring

Pengeboran dengan drill Ø5 mm sedalam 35 mm di 22 titik

$\mathrm{Sv}=0,15 \mathrm{~mm} /$ putaran

$\mathrm{V}=6 \mathrm{~m} / \mathrm{menit}$

$\mathrm{L}=\mathrm{l}+0,3 . \mathrm{d}$

$\mathrm{L}=35+0,3.5=36,5 \mathrm{~mm}$

$$
\begin{aligned}
& \mathrm{Tm}=\frac{\mathrm{L} \cdot \pi \cdot \mathrm{d}}{\text { Sv } \cdot \mathrm{V} \cdot 1000} \\
& \mathrm{Tm}=\frac{36,5 \cdot \pi \cdot 5}{0,15 \cdot 6 \cdot 1000}=0,64 \text { menit }
\end{aligned}
$$

Karena total 22 maka menjadi 14,01 menit

c. Waktu pemesinan grinding

Panjang penggerindaan benda $(\mathrm{l})=550 \mathrm{~mm}$

Lebar penggerindaan benda (b) $=450 \mathrm{~mm}$ )

Tebal total penggerindaan $(\mathrm{h})=0,4 \mathrm{~mm}$

Tebal penggerindaan $(\mathrm{t})=0,1 \mathrm{~mm}$

Lebar pemakanan (s) = $50 \mathrm{~mm} /$ langkah

Kecepatan potong $(\mathrm{V})=10 \mathrm{~m} / \mathrm{menit}$

Jumlah langkah pemakanan,

$$
\begin{aligned}
& \mathrm{x}=\frac{550}{50}=11 \text { langkah } \mathrm{x} 4=44 \text { kali } \\
& \operatorname{Tm}=\frac{1 \cdot \mathrm{b} \cdot \mathrm{x}}{\mathrm{V} \cdot 1000 \cdot \mathrm{s}} \\
& \mathrm{Tm}=\frac{550 \cdot 450 \cdot 44}{10 \cdot 1000 \cdot 50} \\
& \operatorname{Tm}=21,78 \text { menit }
\end{aligned}
$$

Dari hasil perhitungan di atas dengan persamaan yang sama maka didapat hasil waktu pemesinan cetakan seperti Tabel 2.

Tabel 2. Waktu pemesinan komponen cetakan.

\begin{tabular}{clcccccc}
\hline \multirow{2}{*}{ No } & \multirow{2}{*}{ Komponen } & \multirow{2}{*}{ Qty } & \multicolumn{4}{c}{ Waktu Kerja Mesin (menit) } & \multirow{2}{*}{ K } \\
\cline { 3 - 6 } & & 1 & F & BK & G & CNC & \\
\hline 1 & Cavity Plate & 8 & 572 & 259 & 92 & - & 15 \\
2 & Cavity Insert & 1 & 2968 & 259 & 91 & - & 10 \\
3 & Core Plate & 8 & 572 & 186 & 87 & 59 & 10 \\
4 & Core Insert & 1 & 345 & 154 & 62 & - & 10 \\
5 & Ejector Retainer Plate & 2 & 256 & 84 & 29 & - & 10 \\
6 & Spacer Block & 1 & 545 & 159 & 32 & - & 10 \\
7 & Ejector Plate & 1 & 286 & 195 & 108 & - & 10 \\
8 & Clamping Plate Upper & 1 & 286 & 141 & 108 & - & 10 \\
9 & Clamping Plate Support & 1 & 186 & 141 & 88,4 & - & 10 \\
10 & Support Plate & & & & & & \\
\hline
\end{tabular}




\section{PEMBAHASAN}

\section{Analisis Hasil Simulasi Cetakan Software}

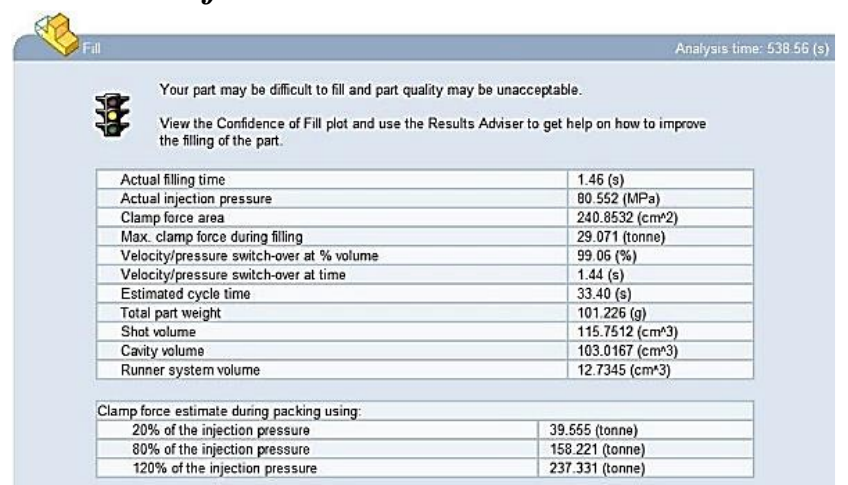

Gambar 5. Ringkasan hasil simulasi software.

Hasil penginjeksian yang baik dapat dilihat pada layar yaitu berdasarkan warna pada produk. Untuk melihat data hasil penginjeksian dapat dilihat pada file mold fill analysis.

\section{Kualitas Produk}

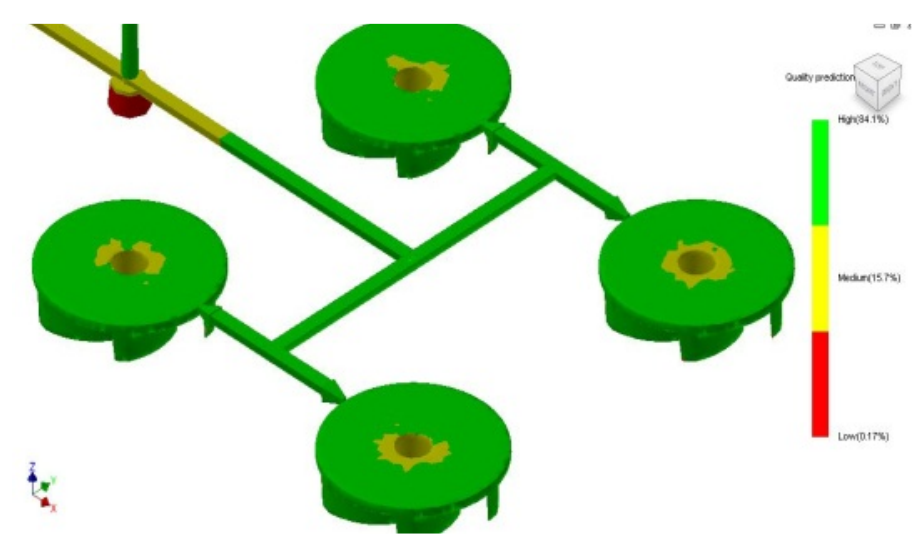

Gambar 6. Warna hasil kualitas produk

Pada layar terdapat warna hijau (high) yang merupakan kualitas tinggi yaitu 70-95\%, kuning (medium) kualitas sedang 40-69\% dan merah (low) untuk kualitas rendah 0,17-39\%. Dalam menganalisa kualitas produk dapat diketahui dengan melihat warna yang timbul pada produk dan keterangan prosentase pada layar [8-10]. Hasil di atas menunjukan bahwa produk sebagian besar memiliki warna hijau dengan kualitas $90 \%$ dan pada tengah terdapat warna kuning $60 \%$ maka dapat disimpulkan bahwa produk memiliki kualitas tinggi rata-rata 75\%.

\section{Waktu Pengisian}

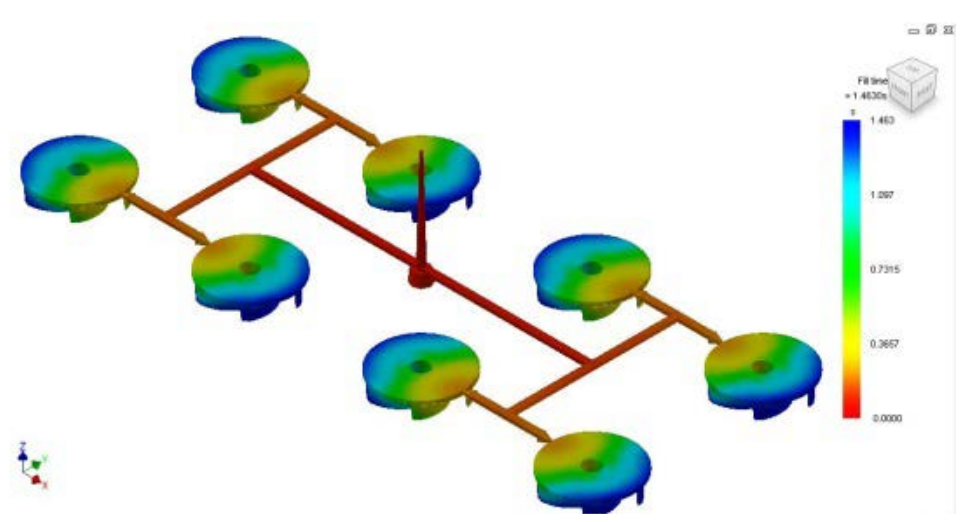

Gambar 7. Warna waktu injeksi plastik. 
Pada layar terdapat kombinasi warna dari merah 0 detik sampai biru tua 1,46 detik. Melihat dari keterangan indikasi gambar, keseimbangan waktu pengisian pada ujung cetakan terisi penuh dengan warna biru tua pada 1,46 detik dan setelah itu memerlukan waktu 5 detik untuk proses pendinginan sebelum cetakan dibuka.

\section{Keseimbangan Pengisian}

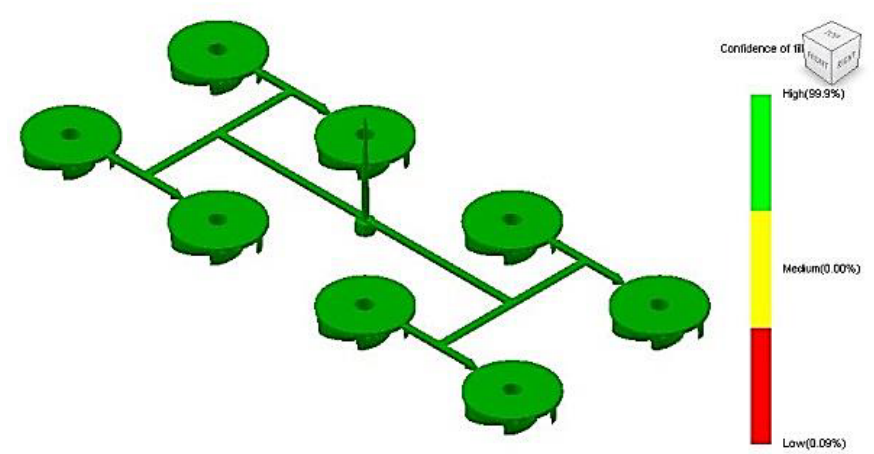

Gambar 8. Keseimbangan injeksi plastik

Pada gambar di atas dapat dilihat untuk warna pada keseimbangan pengisian dari low 0,00\%, medium 0,00\%, dan high 99,9\%. Warna hijau menunjukan bahwa pengisian pada rongga cetakan telah terisi penuh 99,9\% dapat dilihat dari mulai masuk sprue 99,9\% hingga titik bawah rongga cetakan yang berarti menunjukan sistem pengisian sudah optimal.

\section{Air Traps}

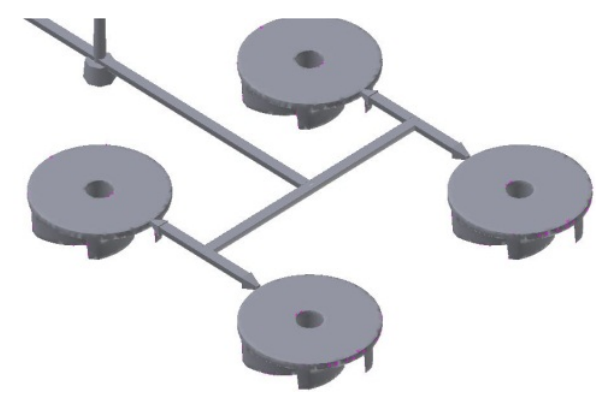

Gambar 9. Udara terjebak pada rongga cetakan

Hasil dari mold fill analysis dapat juga digunakan untuk mengetahui letak udara yang terjebak (Air traps) pada rongga cetakan [11]. Titik-titik berwarna merah muda pada gambar merupakan udara-udara yang terjebak dengan rata-rata ukuran diameter air traps yaitu 0,5 mm. Dalam hal ini masih dalam batas toleransi 0,2 - 0,8 mm untuk luas penampang produk 2000-3000 mm dan dapat diantisipasi dengan ventilasi (vent) pada cavity insert.

\section{Garis Retakan}

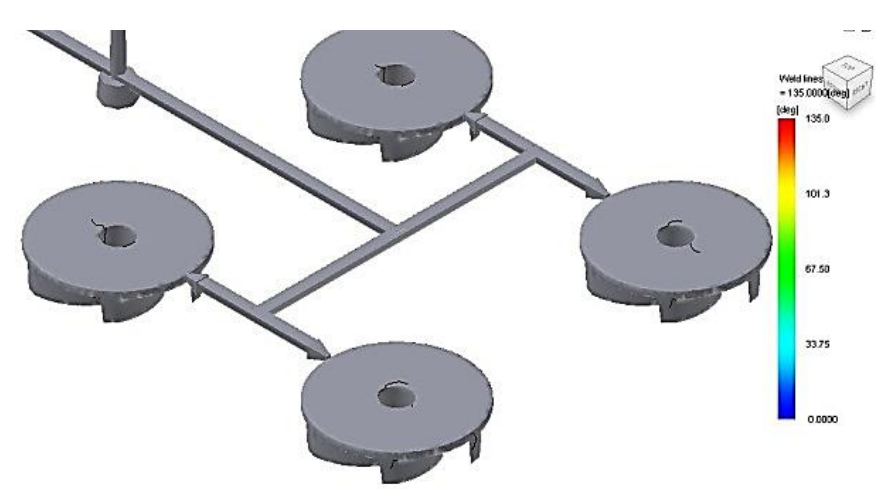

Gambar 10. Garis retakan pada produk 
Adanya lokasi garis retakan pada bagian produk menunjukan bahwa produk belum semuanya sempurna. Warna biru sampai merah menunjukan besarnya garis retakan pada produk yaitu $0^{\circ}$ sampai dengan $135^{\circ}$ dengan batas toleransi untuk mendapatkan kualitas produk yang baik yaitu 67,5 [13-14]. Melihat gambar diatas dapat dilihat warna garis retakan rata-rata berwarna biru muda $30^{\circ}$ hingga biru tua $10^{\circ}$. Maka rata-rata garis retakan yang timbul yaitu $20^{\circ}$.

\section{Analisis Biaya dan Harga Impeller}

Produksi impeller diprediksikan bertahan 1 tahun dikarenakan kemungkinan perbaikan model. Maka, Biaya total yang dikeluarkan dalam 1 tahun produksi adalah seperti pada Tabel 3 di bawah.

Tabel 3. Total biaya produksi

\begin{tabular}{lr}
\hline \multicolumn{1}{c}{ Jeis Biaya } & Total Biaya (Rp) \\
\hline Biaya proses pemesinan & 32.636 .600 \\
Biaya Komponen Standar & 4.442 .507 \\
Biaya Materia Cetakan & 12.885 .340 \\
Biaya Bahan Baku Plastik & 337.174 .731 \\
Biaya Jasa Proses Injeksi & 431.250 .000 \\
Overhead & 50.000 .000 \\
Lain-lain & 30.000 .000 \\
\hline Total & 898.391 .178 \\
\hline
\end{tabular}

Maka, harga per unit impeller bisa ditentukan sebagai berikut,

Harga per unit $=\frac{\text { Total biaya } 1 \text { tahun }}{\text { Total produk dalam } 1 \text { tahun }}$

Total produk 1 tahun jika diasumsikan per bulan 20 hari kerja dam 8 jam per hari maka, total produk 1 tahun yaitu:

Total produk 1 tahun $=1$ siklus $\times 8$ produk $\times 8$ jam $\times 20$ hari $\times 12$ bulan

$$
=(58 \times 8 \times 7 \times 20 \times 12)=779.520 \mathrm{pc}
$$

Prediksi cacat produk (reject) adalah $5 \%$ jadi,

$$
\begin{aligned}
& =779.520-(779.520 \times 5 \%) \\
& =740.544 \mathrm{pc}
\end{aligned}
$$

Asumsi target $=750.000 \mathrm{pc}$

$$
\begin{aligned}
\text { Harga per unit } & =\frac{\operatorname{Rp} 868.391 .178,-}{750.000 \mathrm{pc}} \\
& =\operatorname{Rp} 1.158,- \text { per unit }
\end{aligned}
$$

Dari harga tersebut bisa dapat diasumsikan impeller tersebut dijual dengan harga Rp 5.000,s/d Rp 10.000,- masih jauh lebih murah dari harga impeller import.

\section{SIMPULAN}

Hasil penelitian dari keseluruhan proses perancangan cetakan, simulasi dan pembahasannya pada penelitian ini, dapat diambil beberapa kesimpulan sebagai berikut:

1. Desain perancangan cetakan dan parameter pengerjaan cetak injeksi pembuatan impeller plastik ini menggunakan bahan polimer nilon PA66 dengan desain moldbase menggunakan cetakan two plate HASCO K251 dan parameter volume sekali injeksi $126.674 \mathrm{~mm}^{3}$, tekanan injeksi 80,552 Mpa, suhu cairan plastik $281,1^{\circ} \mathrm{C}$, suhu cetakan $71,1^{\circ} \mathrm{C}$, gaya clamping $601.650 \mathrm{~kg}$, kapasitas produksi 58 piece per jam.

2. Harga per unit impeller plastik yaitu Rp. 1.158,- jika dijual dengan harga berkisar Rp. 5.000 10.000,- masih lebih murah 50-70\% dibandingkan dengan impeller plastik import. 


\section{DAFTAR PUSTAKA}

[1] Hariady, S. (2014). Analisa Kerusakan Pompa Sentrifugal 53-101C WTU Sungai Gerong di PT. Pertamina RU III Plaju. Jurnal Desiminasi Teknologi, 29-42.

[2] Saputra, H. (2012). Studi Perancangan Struktur Rangka Bus Menggunakan CAD/CAE. Jurnal Teknik Mesin Volume 5 No. 1, 40-47.

[3] Mulyadi. (2016). Pengaruh Model Speciment Uji Tarik pada Pengelasan Besi Fc-30 di Lihat dari Kekuatan Tarik Pengelasan. Jurnal Rekayasa Energi Manufaktur. Vol 1 No 2 ISSN 2528-3723, 29 - 36

[4] Manfaat, D., \& Jahidin, S. (2013). Rancang Bangun 3D Konstruksi Kapal Berbasis Autodesk Inventor untuk Menganalisa Berat Konstruksi. Jurnal Teknik Pomits Vol. 2, No. 1, ISSN: 2337-3539.

[5] Yogi Setiawan, Faiz Hamzah, Fipka Bisono. (2018), Rancang Bangun Vacuum Clamp sebagai Teknologi Pendukung dalam Pengerjaan Kayu pada Mesin Cnc Router 3 Axis, Proceedings Conference on Design Manufacture Engineering and its Application, Politeknik Perkapalan Negeri Surabaya, e-ISSN No.2654-8631, 123-127

[6] R. A Malloy, Palstic Part Design for Injection Molding - An Introduction, Hanser Gardner Publications, Cincinnati, Ohio; 1994

[7] Dym. (1979). Injection Mould and Moulding a Practical Manual. New York: Von Nonstran Co Inc.

[8] Fouz, I. (2001). Fluids Mechanics. Oxford: Mechanical Engineering Dept. University of Oxford.

[9] Gastrow. (1983). Injection Mould: 102 Proven Design. New York: MacMillan Publishing Co Inc.

[10] Handayani, D. (2005). Computer Aided Design/Computer Aided Manufactur [CAD/CAM]. Jurnal Teknologi Informasi DINAMIK, 143-149.

[11] Irwan Yulianto, R. H. (2014). Rancangan Desain Mold Produk Knob Regulator Kompor Gas Pada Proses Injection Molding. Institut Teknologi Nasional.

[12] Johannaber, F. (1983). Injection Molding of Machines: A User's Guide. New York: MacMillan Publishing Co Inc.

[13] Manfaat, D., \& Jahidin, S. (2013). Rancang Bangun 3D Konstruksi Kapal Berbasis Autodesk Inventor untuk Menganalisa Berat Konstruksi. Jurnal Teknik Pomits Vol. 2, No. 1, ISSN: 2337-3539.

[14] Saputra, H. (2012). Studi Perancangan Struktur Rangka Bus Menggunakan CAD/CAE. Jurnal Teknik Mesin Volume 5 No. 1, 40-47. 